\title{
How Different Diversity Factors Affect the Perception of First- Year Requirements in Higher Education
}

\author{
Carla Bohndick ${ }^{1}$, Elke Bosse², Vanessa K. Jänsch'1 , \& Miriam Barnat ${ }^{3}$ \\ ${ }^{1}$ University of Hamburg, Germany \\ ${ }^{2}$ HIS-HE, Germany \\ ${ }^{3}$ University of Applied Sciences Aachen, Germany
}

Article received 27 April 2020 / Article revised 29 September / Accepted 19 November / Available online 12 March 2021

\begin{abstract}
In the light of growing university entry rates, higher education institutions not only serve larger numbers of students, but also seek to meet first-year students' ever more diverse needs. Yet to inform universities how to support the transition to higher education, research only offers limited insights. Current studies tend to either focus on the individual factors that affect student success or they highlight students' social background and their educational biography in order to examine the achievement of selected, nontraditional groups of students. Both lines of research appear to lack integration and often fail to take organisational diversity into account, such as different types of higher education institutions or degree programmes. For a more comprehensive understanding of student diversity, the present study includes individual, social and organisational factors. To gain insights into their role for the transition to higher education, we examine how the different factors affect the students' perception of the formal and informal requirements of the first year as more or less difficult to cope with. As the perceived requirements result from both the characteristics of the students and the institutional context, they allow to investigate transition at the interface of the micro and the meso level of higher education. Latent profile analyses revealed that there are no profiles with complex patterns of perception of the first-year requirements, but the identified groups rather differ in the overall level of perceived challenges. Moreover, SEM indicates that the differences in the perception largely depend on the individual factors self-efficacy and volition.
\end{abstract}

Keywords: study requirements; self-efficacy; volition; structural barriers; organisational diversity

Corresponding author: Carla Bohndick, University of Hamburg, Hamburg Center of University Teaching and Learning, Schlüterstr. 51, $20146 \quad$ Hamburg, Germany. Email: carla.bohndick@uni-hamburg.de DOI:https://doi.org/10.14786/flr.v9i2.667 


\section{Introduction}

In Germany, university enrolment rates have doubled over the last ten years, currently reaching over 50 percent. ${ }^{1}$ At the same time, the average drop-out rate has remained relatively high (ca. $30 \%$ ), yet it no longer tends to occur towards the end of studies, but during the first year. While early drop-out is a known phenomenon internationally (OECD, 2019), the shift towards the first year in Germany is regarded as an effect of the implementation of bachelor's and master's degree programmes, which brought along accumulated demands for first-year students (Heublein et al., 2017). Assessment, for example, used to be mainly based on the final year, whereas the reform included introducing exams from early on, so that in many study programmes failure leads to dismissal and drop-out decisions cannot be postponed towards the end of studies. Thus, in addition to the challenges of academic and social integration, first-year students face personal and organisational requirements such as coping with the pressure to perform and dealing with the assessment system (Trautwein \& Bosse, 2017). As a consequence of this latest development, the transition to higher education (HE) is an important issue on the political agenda in Germany and many universities have expanded their first-year support activities in order to facilitate study success. In line with the political goal of widening participation, there is a particular concern "to meet the educational needs of an ever more diverse group of learners" (Schuetze \& Slowey, 2002, p. 310), just as in many countries worldwide.

To inform policy and practice, a growing body of research provides insights into the transition to HE (Coertjens, Brahm, Trautwein, \& Lindblom-Ylänne, 2017; Jenert, Postareff, Brahm, \& LindblomYlänne, 2015; Kyndt, Donche, Trigwell, \& Lindblom-Ylänne, 2017). Focusing on the micro level of student development, the major line of research investigates factors associated with study success and allows capturing diversity in terms of individual variables and profiles (De Clercq, Galand, \& Frenay, 2017; Haarala-Muhonen, Ruohoniemi, Parpala, Komulainen, \& Lindblom-Ylänne, 2017). This psychological perspective is complemented by another strand of research that foregrounds differences in students' educational biography, entry routes and mode of study in order to gain insight into the participation of traditionally underrepresented groups of students (Schuetze \& Slowey, 2002). The respective studies take social diversity factors (e.g., educational background) into account that allow to examine the socially selective access to $\mathrm{HE}$ as well as the particular challenges experienced by nontraditional students (Holmegaard, Madsen, \& Ulriksen, 2017; Schindler \& Lörz, 2011). Hence, they address questions of social inequality and structural barriers in HE and allow to shed light on the macro level of the wider educational system.

The abovementioned effects of the latest reforms in Germany illustrate the impact of (changes in) the institutional context and therefore suggest to go beyond individual student characteristics in order to shed light on factors within a university's control (Bernardo et al., 2016). In fact, there is a need to gain further insights into the institutional context as well as the impact of different diversity factors. The present paper therefore seeks to examine the interface between the micro level of the individual student experience and the meso level of the institutional context in terms of the students' perception of firstyear requirements. By including individual variables relevant for study success as predictors of this perception, it follows a person-centred approach and at the same time, the study investigates the effects of the students' social diversity as well as organisational differences related to the HE system (e.g., study programmes). Before presenting the methods and results of our study, we explain the theoretical assumptions and provide an overview of previous research on both first-year requirements and the role of diversity for study success.

\footnotetext{
${ }^{1}$ For current figures see: https://www.datenportal.bmbf.de/portal/en/B25.html
} 


\section{Perception of First-Year Requirements}

Previous research that includes both individual student factors and the institutional context shows only limited effects of, for example, curriculum design and approaches to teaching on study success (Berg \& Hofman, 2005; Jansen, 2004). The present study takes an alternative route, as it shifts the focus towards first-year students' individual perception of institutional requirements as important factors for successful transition to HE. In our theoretical framework, the perceived requirements are assumed to represent the interface of the student and the context level of HE as they reflect both individual experiences and the characteristics of the institutional context. This assumption is based on a study on the transition to HE, which expanded the traditional notion of academic and social integration (Tinto, 1987) by introducing the distinction of personal, organisational, content-related, and social requirements (Trautwein \& Bosse, 2017).

According to the explorative interview study of Trautwein and Bosse (2017), personal requirements are related to the students' self-management and adjustment to student life (e.g., to manage the workload), whereas organisational requirements result from rules and regulations as well as the teaching conditions (e.g., to manage the course selection). Furthermore, content-related requirements concern the subject matter of the study programme (e.g., to meet curricular demands). Finally, social requirements regard relationships, communication and cooperation with peers and staff (e.g., to collaborate in teams). Following a mixed-methods-approach (Barnat, Bosse, \& Trautwein, 2017), this taxonomy was further developed by a longitudinal survey at four German universities (Jänsch \& Bosse, 2018). The study confirmed the four different dimensions of the first-year requirements, while factor analyses resulted in six factors that represent the key challenges for first year students (see Table 1). Drawing on the findings, Jänsch and Bosse (2018) validated the instrument and examined the perception of first-year requirements in their relation with self-reported measures of study success. They found that all of the examined requirements show positive relationships with subjective study performance and study satisfaction. Apart from the introduction of the instrument in the context of quality management (Barnat, Bosse, \& Mergner, 2017), it has been translated to the Belgian university context (Dangoisse, De Clercq, Van Meenen, Chartier, \& Nils, 2019; De Clercq, Van Meenen, \& Frenay, 2020).

In the light of the political and practical relevance of student diversity, the reported findings raise the question whether the different first-year requirements pose an equal challenge for all students and to what extent diversity factors have an impact on the perceived requirements. Previous research on the role of diversity in HE may therefore inform further investigation.

\section{Diversity in higher education}

The theoretical framework of our study not only distinguishes between the different levels of the HE system, locating the first-year requirements at the interface of the micro level of the individual student and the meso level of the institutional context. In fact, it also adopts a comprehensive notion of student diversity, including social, individual and organisational factors (Bosse, 2015). Drawing on the previous research on the transition to HE mentioned above, we propose that the perception of first-year requirements depends on the diversity in terms of the students' individual, performance-related differences as well as social differences related to the students' background. Furthermore, we suppose that a third dimension of diversity needs to be considered, as organisational differences in the types of institution and the students' participation in specific study programmes may also influence the perception of institutional requirements.

The diversity factors intersect with the analytical levels of the micro-meso-macro-framework as they may first explain student learning and development, second, they can be relevant for understanding 
the academic performance in a specific institutional context and finally they may serve to interpret the general patterns of participation and success in the wider HE system. Thus, including both the different levels and diversity factors leads to a two-dimensional framework that allows to explore and explain differential experiences and outcomes in HE (Mountford-Zimdars, Sabri, Moore, Sanders, Jones, \& Higham, 2015). Illustrating the theoretical framework, Figure 1 shows that our study seeks to shed light on the effects of diversity on students' perception of first-year requirements that are located at the interface of the micro and the meso level of HE.

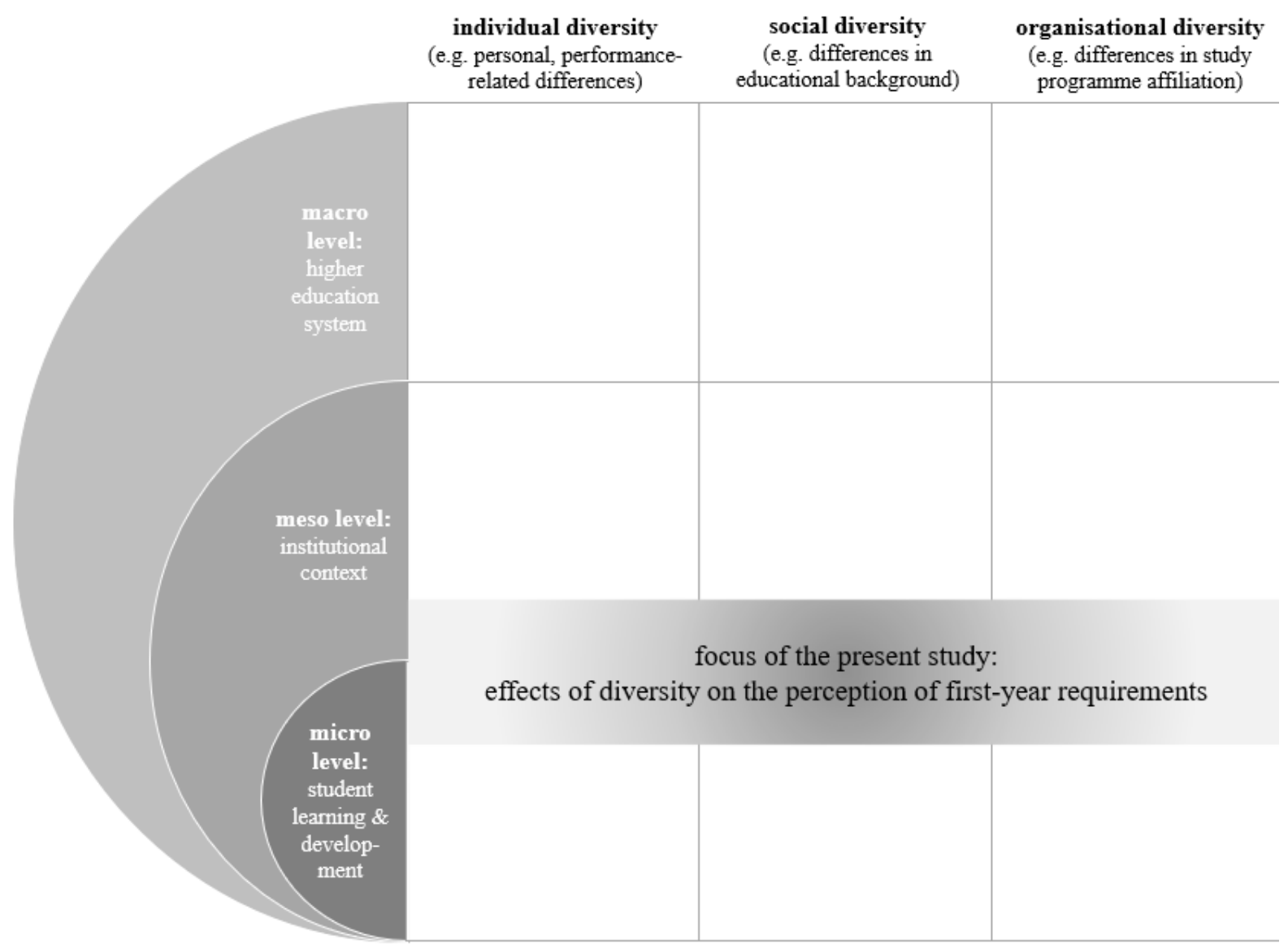

Figure 1: Theoretical framework integrating the levels of $\mathrm{HE}$ and the dimensions of diversity

So far, research has not yet addressed the particular role of the different diversity factors for the perception of first-year requirements. However, as indicated by research on the relationship between requirements and study success (Jänsch \& Bosse, 2018), findings on study success and retention may serve as a starting point to identify and select relevant diversity factors for further examination. While our framework implies that individual, social and organisational diversity factors theoretically may affect each of the three levels of HE, the findings reported in the following reveal that up to now individual diversity tends to be linked to the micro level, social diversity is often used to shed light on the macro level and organisational diversity seems to be mostly connected with the meso level.

\subsection{Individual diversity factors}

From a psychological perspective, differences in student performance can be explained through individual abilities and motivation. Mainly providing insights into the micro level of HE, there are several individual diversity factors that are found to be important for study success and may also affect the perception of institutional requirements. 
A meta-analysis came to the conclusion that besides cognitive factors, three individual nonintellective factors are most important for study success: self-efficacy, grade goal, and effort regulation (Richardson, Abraham, \& Bond, 2012, see also Schneider \& Preckel, 2017). Self-efficacy is defined as the perceptions of academic capability (Richardson et al., 2012). This definition goes back to the efficacy expectancies by Bandura (1997), and the construct is widely accepted as very important for study success (Bartimote-Aufflick, Bridgeman, Walker, Sharma, \& Smith, 2016). In the meta-analysis, grade goal is the self-assigned goal standard (Richardson et al., 2012). As such it is similar to the construct of goal commitment (Locke, Latham, \& Erez, 1988), i.e., the intensity to which students feel committed to finish their studies. In current literature reviews, commitment to meaningful personal goals is also extracted as an important factor for study success (Gonida \& Peixoto, 2019). Effort regulation is part of self-regulatory learning strategies and refers to volitional aspects like the persistence and effort when faced with challenging academic situations (Richardson et al., 2012). The importance of these volitional aspects is also emphasized in recent studies (e.g., Asikainen, Hailikari, Mattsson, 2018; Duchatelet \& Donche, 2019).

\subsection{Social diversity factors}

Differences in study success can also be viewed as a matter of educational inequalities on the macro level of HE that result from structural barriers for specific social groups of students (e.g., traditional and non-traditional students). Thus, social diversity factors related to student participation and socialisation may influence the perception of first-year requirements. The most relevant factors include (1) the family background, (2) the educational biography (e.g., type of HE qualification), (3) characteristics of the general life situation.

Regarding the family background, the students' background in terms of education counts as an important factor, as first-generation students have long been regarded a special group in research on study success and retention (Pascarella, Pierson, Wolniak, \& Terenzini, 2004). Furthermore, research on HE in Germany suggests that students with migration background leave their studies more often than other students (Ebert \& Heublein, 2017). In Germany, there are different educational pathways to qualify for HE. Typically, students complete the Gymnasium and their Abitur provides a general university entrance qualification. However, there are more and more alternative ways to qualify for HE, for example through vocational training. Studies show that students with a general university entrance qualification are more successful in their studies than other students (Heublein et al., 2017; Schindler, 2014). Finally, the general life situation is an important aspect to be taken into account regarding firstyear requirements. Especially the health status and factors impeding the time budget for studying have to be considered. Health problems can be a reason for study drop out (Heublein et al., 2017). The same applies to study burdens caused by employment (Brandstätter, Grillich, \& Farthofer, 2006), parenthood and other care obligations. All in all, the social factors not only play a role individually as former research has shown but also are in interplay and reinforce each other. Therefore, a necessary next step takes all the aspects together and analyses the agglomerated impact of social factors.

\subsection{Organisational diversity factors}

Focusing on the HE system from an organisational perspective contributes to the explanation of differences in study success by highlighting the institutional context, which shapes the learning environment on the meso level of HE. Since behaviour is always influenced by both person and situation, it is crucial to take organisational diversity factors into account - especially their interplay with the individual and social factors (Bohndick, Rosman, Kohlmeyer, \& Buhl, 2018). Since the organisational perspective is often neglected in studies on study success, there is little evidence which factors are the most important. 
For possible influences of organisational factors on the perception of institutional requirements, the types of HE institutions need to be considered as in Germany there are either research universities or universities of applied sciences (Kehm, 2010). Both types show considerable differences with regard to student drop-out and success rates, just as success varies according to the fields of study (Heublein, Richter, \& Schmelzer, 2020). Research on study requirements also reveals that requirements must be considered depending on the field of study (Bohndick \& Buhl, 2014; Hell, Ptok, \& Schuler, 2007). Furthermore, Bülow-Schramm (2018) found that the student composition of single study programmes is rather homogeneous, while diversity rather shows between the disciplines. Therefore, it can be expected that there are different relationships between individual and social diversity and the requirements for organisational diversity regarding (a) the types of HE institution and (b) different fields of study.

\section{Research Questions}

The aim of this paper is to investigate the transition to HE by taking individual, social and organisational diversity factors into account. In order to do so, we chose to follow a two-step procedure: First we want to take a deeper look at the first-year requirements as a representation of the interface of the micro and meso level of HE. Here, especially research on typical patterns regarding the perception of the requirements is needed. Second, we attempt to explain differences in the perceptions by including a range of different diversity factors. By searching for different student profiles and examining the effects of individual, social and organisational variables, the paper intends to further explore the role of diversity for the transition to HE. Derived from the current state of research, our study is guided by two research questions:

The first research question is: Are there distinct profiles in regard to first-year students' perception of institutional requirements? As previous research reveals various effects of diversity on study success, we assume that there might be distinct groups of students who perceive the requirements differently. However, there is no research to date regarding typical patterns of the requirements and no research allowing us to deduce possible patterns. Building on research on profiles of entrance variables (De Clercq et al., 2017), we nonetheless expect to find complex profiles with combinations of high and low scores for the different requirements.

The second research question aims at taking several diversity factors at the same time into account: To what extent is the first-year students' perception of institutional requirements influenced by individual variables (e.g., self-efficacy) and social variables (e.g., educational background) and is this relationship moderated by organisational variables (e.g., type of HE institution)?

\section{Method}

The study is based on a student survey conducted at four German HE institutions. Data were collected shortly after the first year of university, resulting in a final sample of 1,347 participants from a broad range of different bachelor's degree programmes, for example engineering, humanities, math, sciences, law, economy, social studies, and medicine. The students had a mean age of 22.96 years (SD $=4.97), 61.1 \%$ identified as women, $1 \%$ did neither identify as women nor as men. Except for the minimally larger percentage of female students, the composition of the sample can be regarded as representative for the German student population as German students start university at a slightly older age than in many other countries. 


\subsection{Instruments}

\subsubsection{Requirements}

Students' perception of the institutional requirements was measured with the MWS ("Messinstrument für die Wahrnehmung von Studienanforderungen", Jänsch \& Bosse, 2018). The MWS is based on the findings of Trautwein \& Bosse (2017) and measures the four dimensions of requirements with 21 items pertaining to six factors. As listed in Table 1, the six factors comprise the adjustment to the academic mode, the development of subject interest and engagement in applied learning, the organisation of learning activities, the handling of the pressure to perform and failure, the management of the formal study organisation and finally, the establishment of social relationships and the management of teamwork. For all items of the scale see Appendix A. Students were asked to indicate how challenging they found handling the requirements in their first year on a scale from 1 being "difficult to handle" to 5 "easy to handle". The descriptive results for these factors are depicted in Table 1. The internal consistency was good.

\subsubsection{Diversity Factors}

For the second research question, the questionnaire included individual, social and organisational variables. For the individual variables self-efficacy, goal commitment, and volition (here: action control), the participants were asked to rate different statements on a scale from 1 being "does not apply" to 5 "does apply perfectly". The descriptives are displayed in Table 1.

Table 1

Measurement instruments

\begin{tabular}{|c|c|c|c|c|c|}
\hline Measures & $\begin{array}{r}\text { No. of } \\
\text { items }\end{array}$ & $\alpha$ & $\mathrm{M}$ & $\mathrm{SD}$ & Source \\
\hline Requirements & & & & & $\begin{array}{c}\text { Jänsch \& } \\
\text { Bosse, } 2018\end{array}$ \\
\hline content-related: academic mode & 3 & .83 & 3.58 & .83 & \\
\hline content-related: subject interest \& appl. learning & 3 & .69 & 3.51 & .79 & \\
\hline personal: learning activities & 4 & .78 & 3.22 & .76 & \\
\hline personal: pressure to perform $\&$ failure & 3 & .71 & 3.33 & .78 & \\
\hline organisational: study organisation & 4 & .62 & 3.51 & .71 & \\
\hline social: relationships \& teamwork & 4 & .79 & 3.77 & .81 & \\
\hline \multicolumn{6}{|l|}{ Individual diversity } \\
\hline Self-efficacy & 3 & .80 & 3.77 & 0.77 & $\begin{array}{l}\text { Tönnies et } \\
\text { al. } 1996\end{array}$ \\
\hline Goal commitment & 3 & .83 & 4.42 & 0.67 & $\begin{array}{c}\text { Hußtegge, } \\
2011\end{array}$ \\
\hline Volition (Action control) & 4 & .85 & 3.07 & 0.93 & $\begin{array}{c}\text { Hußtegge, } \\
2011\end{array}$ \\
\hline Social factors & 7 & - & 0.26 & 0.86 & $\begin{array}{c}\text { own } \\
\text { development }\end{array}$ \\
\hline
\end{tabular}

Note. Number of items, Means (M), Standard deviations (SD) and Cronbach's Alpha ( $\alpha$ ) 
Social diversity was measured with single items referring to seven characteristics commonly used to distinguish traditional and non-traditional students (Schuetze \& Slowey, 2002) and additionally known to make studying more difficult. To account not only for the interplay of the characteristics but also for their mutual reinforcement, the seven aspects were summed up to a total score for social factors ( $\min =0, \max =7$ ). With a mean of $M=0.26$ and a median of med $=0$, the distribution is positively skewed, indicating that there are only few students with high scores on the social factors.

The following list shows the factors included in our study and specifies the characteristics of our sample:

- family educational background (parents without university degree $(52.2 \%)$ vs. one or two parents with university degree)

- type of HE qualification (no general university entrance qualification (35.8 \%) vs. general university entrance qualification)

- migration background (no parents born in Germany (14.4\%) vs. one or both parents born in Germany)

- health status (disability regarded as an impairment for studies (27.4\%) vs. no disability or disability not regarded as an impairment for studies)

- employment (more than 10 hours employment parallel to studies $(29.8 \%)$ vs. no employment or less than 10 hours employment)

- parenthood (children regarded as an impairment for studies $(0.7 \%)$ vs. no children or children not regarded as an impairment for studies)

- other care obligations (e.g., care for family members with health issues $(9.6 \%)$ vs. no other care obligations)

For organisational diversity, we collected information regarding the type of HE institution (universities and universities of applied sciences) and the field of study (engineering; humanities; math $\&$ science; law, economy \& social studies; medicine \& health; other). The number of participants for each group is shown in Table 3.

\section{Findings}

\subsection{Research question 1: Profiles of the perception of first-year requirements}

To address our first research question, we used latent profile analysis (Marsh, Lüdtke, Trautwein $\&$ Morin, 2009) to cluster the students by the six factors of institutional requirements. To identify the number of subgroups, we compared fit-indices of solutions with 1 profile to 9 profiles. Table 2 shows the Bayesian information criterion (BIC), the integrated completed likelihood (ICL), and the bootstrapped likelihood-ratio test and its significance level (BLRT). Compared with other profile solutions, the best fitting solution should have the BIC and ICL which is closest to zero, the BLRT should be significant $(\mathrm{p}<.05)$, none of the profiles should be smaller than $10 \%$. Additionally, the final profile solution should make sense theoretically (Marsh et al., 2009). 
Table 2

Fit indices for the different profile solutions

\begin{tabular}{lllll}
\hline $\begin{array}{l}\text { No of } \\
\text { profiles }\end{array}$ & BIC & ICL & BLRT & $\begin{array}{l}\text { Smallest } \\
\text { profile }\end{array}$ \\
\hline 1 & -18628.95 & -18628.95 & sig. & $100 \%$ \\
2 & -18491.03 & -18996.04 & sig. & $34 \%$ \\
3 & -18391.99 & -18960.10 & sig. & $<10 \%$ \\
4 & -18393.58 & -19232.91 & sig. & $<10 \%$ \\
5 & -18405.49 & -19199.19 & sig. & $<10 \%$ \\
6 & -18421.39 & -19368.19 & n.sig. & $<10 \%$ \\
7 & -18459.49 & -19484.25 & - & $<10 \%$ \\
8 & -18497.16 & -19519.16 & - & $<10 \%$ \\
9 & -18541.27 & -19697.53 & - & $<10 \%$
\end{tabular}

Note. BIC: Bayesian information criterion, ICL: Integrated completed likelihood, BLRT: significance level of the boot-strapped likelihood test

BIC, ICL and BLRT are similar for most of the profiles. A look at the smallest profile reveals that the criterion is only met by the 1-profile and the 2-profile solution. We inspected the different solutions and the overarching result was that the profiles in the different solutions mostly differ with regard to their level of perceived challenges and differed mainly in the number of parallel profiles in between. See for example the 2-profile solution in Figure 2. Here, we have two groups of students. The first profile $\mathrm{X} 1(\mathrm{n}=795)$ is characterised by a perception of all tested requirements as rather difficult. We can call this profile "students perceiving requirements as difficult". The second profile X2 $(n=412)$ contains students showing above average scores, i.e., they perceive all six requirements almost equally as less challenging. We can call this profile "students perceiving requirements as easy". The results indicate that there are no distinct profiles in regard to first-year students' perception of the single institutional requirements. In fact, Figure 2 shows that the standardised values of the two profiles result in two rather parallel graphs representing the different levels of perceived challenges. The different nature of the single requirements hardly seems to play a role, except for the requirement of organising learning activities, that Profile X1 regards as the most difficult, whereas Profile X2 shows the highest scores. 


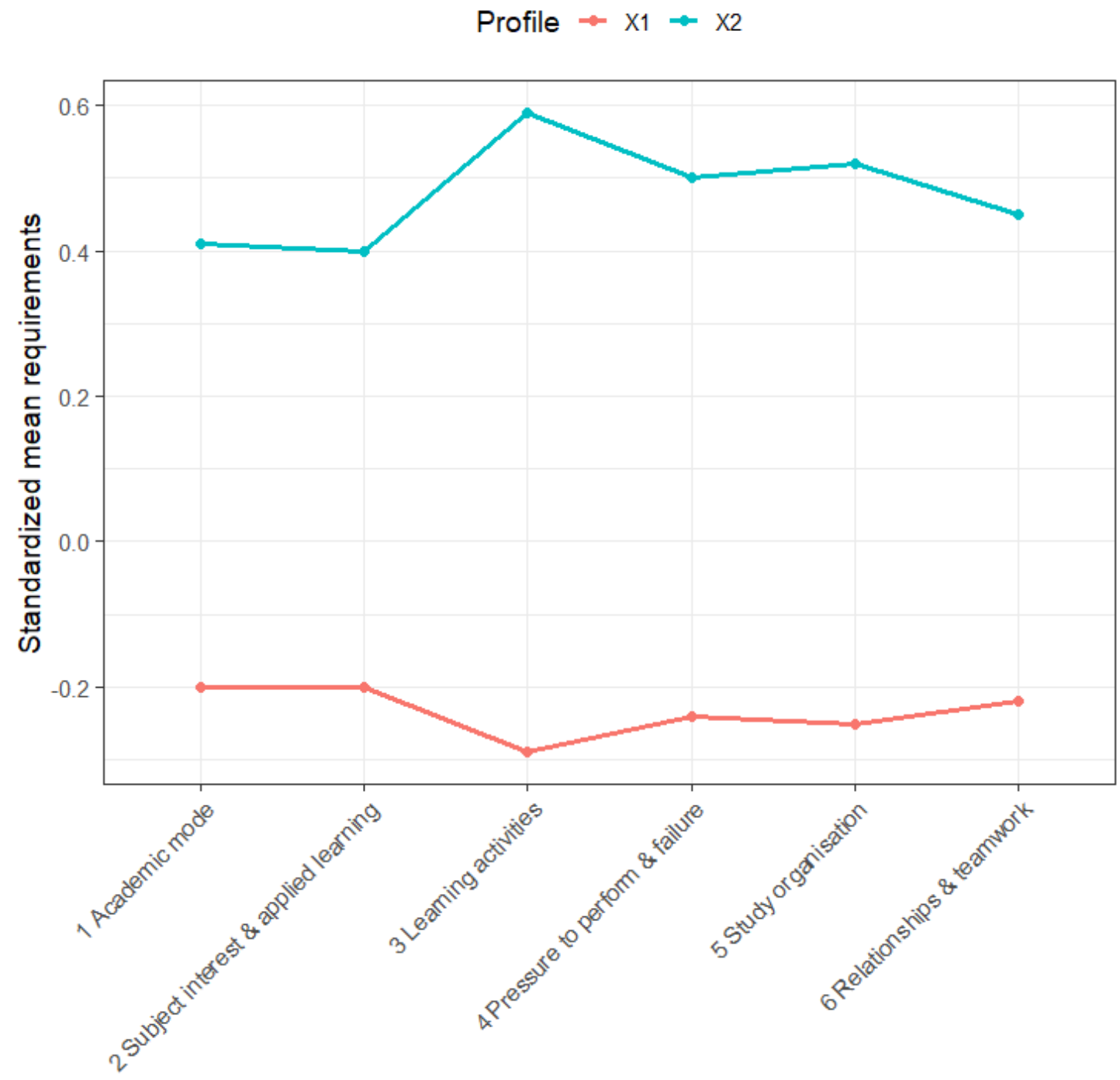

Figure 2: Latent profiles of first-year students' perception of institutional requirements. On the y-axis there are the standardized values of the requirements (i.e., subtracting the mean and dividing through the standard deviation; resulting in a mean of $\mathrm{M}=0$ and a standard deviation of $\mathrm{SD}=1$ ).

\subsection{Research question 2: Relationship between diversity and perception of first-year requirements}

Research question 2 asked which individual, social and organisational factors influence students' perception of institutional requirements. Since the findings for research question 1 suggest that there are no differences in the perception of the single requirements but there are students rating all requirements as hard or easy, for research question 2 we combined all the single requirements to a second order factor "requirements" instead of using the profiles. This was then our endogenous variable in a structural equation model where the predictors for individual and social diversity were included as exogenous variables. In contrast to explaining the profiles with the diversity factors, we decided to rather include the individual perception of the students and not only their affiliation to a profile in order not to lose any information.

Taking the large sample size into consideration (Hair et al., 2009), the model fit was acceptable with $\operatorname{chi}^{2}(98)=478.323, \mathrm{p}<.05 ; \mathrm{CFI}=.945 ;$ RMSEA $=.054$. To analyse if the organisational factors 
moderate the relationship between individual/social factors and the perception of institutional requirements, we estimated the model for multiple groups simultaneously. We did this for the HE types and for the disciplines independently. As a consequence, we have results for three models displayed in Table 3.

Table 3

Results of the structural equation models: Standardized regression coefficients

\begin{tabular}{|c|c|c|c|c|c|c|}
\hline & \multicolumn{5}{|c|}{ Individual factors } & \multirow[b]{2}{*}{$\mathbf{R}^{2}$} \\
\hline & $n$ & Self-efficacy & $\begin{array}{l}\text { Goal } \\
\text { commitment }\end{array}$ & Volition & Social factors & \\
\hline Model 1: Without Groups & 1347 & .38 & .06 & .38 & -.03 & $41.9 \%$ \\
\hline \multicolumn{7}{|l|}{ Model 2: HE Types } \\
\hline $\begin{array}{l}\text { Universities of Applied } \\
\text { Science }\end{array}$ & 399 & .40 & -.00 & .41 & .08 & $44.3 \%$ \\
\hline Research Universities & 948 & .37 & .07 & .39 & -.06 & $41.4 \%$ \\
\hline \multicolumn{7}{|l|}{ Model 3: Field of study } \\
\hline Engineering & 307 & .42 & -.07 & .41 & .02 & $40.6 \%$ \\
\hline Humanities & 115 & .17 & .32 & .19 & -.00 & $22.5 \%$ \\
\hline Math \& Science & 131 & .37 & .01 & .40 & -.07 & $35.2 \%$ \\
\hline $\begin{array}{l}\text { Law, Economy \& Social } \\
\text { Studies }\end{array}$ & 429 & .47 & .02 & .42 & -.03 & $51.3 \%$ \\
\hline Medicine \& Health & 64 & .44 & .14 & .28 & -.06 & $54.2 \%$ \\
\hline Other & 302 & .37 & -.04 & .64 & -.32 & $67.6 \%$ \\
\hline
\end{tabular}

Note. $\mathrm{R}^{2}$ : explained variance in requirements; significant values in bold. The model fit for model 2 was acceptable with $\operatorname{chi}^{2}(392)=830.851, \mathrm{p}<.05 ; \mathrm{CFI}=.937$; RMSEA $=.058$. The model fit for model 3 was acceptable with $\operatorname{chi}^{2}(588)=1095.014, \mathrm{p}<.05 ; \mathrm{CFI}=.928 ; \mathrm{RMSEA}=.062$.

Model 1 is the model excluding the organisational factors. Here, the perception of institutional requirements had a positive significant relationship with self-efficacy $(\beta=.38, p<.05)$ and with volition $(\beta=.38, p<.05)$. Goal commitment and social diversity had no relationships with the perception of the requirements. For model 2, where differences between the types of HE institutions were taken into account, the perception of institutional requirements had a positive significant relationship with selfefficacy $(\beta=.40, p<.05 / \beta=.37, p<.05)$ and volition $(\beta=.41, p<.05 / \beta=.39, p<.05)$. In model 3, we differentiate between the field of studies. For engineering, math \& science, and law, economy \& social studies, the perception of institutional requirements is positively related to self-efficacy $(\beta=.43$, $p<.05 / \beta=.37, p<.05 / \beta=.47, p<.05)$ and to volition $(\beta=.41, p<.05 / \beta=.40, p<.05 / \beta=.42, p<$ $.05)$. For humanities, the perception has a positive relationship with goal commitment $(\beta=.32, p<.05)$. For medicine $\&$ health there are no significant relationships with the predictors. For the remaining fields of study, the perception of institutional requirements is positively related with volition $(\beta=.64, p<.05)$ and negatively related with social diversity $(\beta=-.32, p<.05) . \mathrm{R}^{2}$ ranges between $22.5 \%$ (for humanities) and $67.6 \%$ (for the other fields of studies). 


\section{Discussion}

Research on transition tends to focus on either the individual student or the social structures of the HE system, just as it often foregrounds selected diversity factors to explain differential student experiences and success rates. To broaden this perspective, the theoretical framework of our study combined both the different levels of the HE system and a comprehensive notion of student diversity. This integrated view not only allowed us to go beyond student characteristics and include the institutional context in terms of the first-year requirements, but also served as a gateway to equally address individual, social and organisational diversity factors.

By focusing on first-year students' perception of institutional requirements, our study investigated the interface between the micro level of the student experience and the meso level of the institutional context. Additionally, the perception was examined with regard to individual, social and organisational diversity factors. Questionnaire data from 1,347 first-year students from four different institutions and several fields of study were analysed using latent profile analysis as well as structural equation modelling. Expanding the current research perspectives on the first-year experience, the findings of this study substantially contribute to the understanding of the transition to HE and the relevance of diversity for this process.

Research question 1 asked for distinct profiles in regard to first-year students' perception of institutional requirements. However, latent profile analyses revealed that there are no profiles with complex patterns of perception of the first-year requirements, but the identified groups rather differ in the overall level of perceived challenges. The biggest differences between the two groups exist in the personal requirement to organise learning activities. This result corresponds to the emphasis on learning strategies in former research on transition (e.g., Haarala-Muhonen et al., 2016). At the same time, it may reflect the reported changes in the German HE system and it also broadens the perspective on the wider range of different requirements. Beyond this difference both profiles are almost similar and only differ in the general perception of the requirements. This comes unexpected when comparing the results to former research on combinations of entrance variables (De Clercq et al., 2017) and is especially interesting against the background of individual competence profiles: When assuming that students have different strengths (e.g., social competence) and developmental needs (e.g., organisational competence) more complex patterns would have been more expectable. For example, if one experiences relationships and teamwork as challenging, it is not self-evident that the academic mode is also experienced as challenging. The findings, however, point into a different direction: It seems that the start into a study programme is either easy or difficult altogether with no compensation effects between the single requirements. This points to the interpretation that institutional conditions are beneficial for some of the students - and disadvantageous for others. This underlines the importance to investigate influences of diversity factors as we did in our second research question.

Research question 2 asked how differences in the perception of first-year requirements can be explained by individual, social and organisational diversity factors. Our study indicates that the differences in the perception largely depend on the individual factors self-efficacy and volition. Together with goal commitment and social factors - and without considering the institutional factors - they account for $41.9 \%$ of the variance in the perception of the requirements. The same results are true for both types of HE institution. The importance of individual diversity for the perception of institutional requirements is in line with former findings regarding the predictive nature of these factors for study success (Richardson et al., 2012). However, in light of the assumed centrality of social factors (e.g., Holmegaard et al., 2017; Schindler \& Lörz, 2011) these results are also surprising. A possible explanation are associations between individual factors and social factors which indicate that the structural barriers have deeper influence than expected through the individual factors. In other words, it might be the case that social factors influence the acquisition of relevant skills long before the transition to HE - an assumption that calls for future research that does not foreground selected factors, but further explores the interplay of individual and social factors (Wallis \& Bosse, 2020). 
When taking the field of study into account, the findings are more ambiguous. Two results are particularly interesting: First, while in most of the disciplines self-efficacy and volition were most relevant, they seem to be only of secondary importance for explaining the perception of the requirements in the humanities. Instead, goal commitment shows the highest relationship. This might be due to the special status of the humanities for example regarding the lack of a clear vocational perspective, which also goes in hand with specific motives for studying. Second, even though social factors seem to have no influence when only looking at all fields of study together, the "other" types of studies (combining field of studies with small sample sizes, e.g., arts, sports, or forestry) show an influence. To further clarify this finding, the composition of the student body in the different fields of study needs to be further investigated.

Together with the first finding that the institutional environment seems to be more or less beneficial for the individual student, the identified differences between the disciplines allude to concepts such as the "implied student" (Ulriksen, 2009) or the "ideal student" (Wong \& Chiu, 2019). Focusing on the process of becoming a student, they propose that study programmes are shaped by implicit institutional expectations and ideals about student learning and academic practices, which may favour certain student characteristics over others. This approach could prove valuable for further exploring the differences between the disciplines in order to advance the research on the role of organisational diversity for the transition to HE.

\subsection{Strengths, limitations and implications for further research}

The contribution of our study to the field of research on the transition to HE is to investigate institutional requirements as a means to go beyond individual factors and to include the institutional context as the meso level of HE. In particular, we expanded the insights into general effects by using latent profile analysis as a high-standard approach to identify specific groups of students who differ in their perception of the first-year requirements. Furthermore, our study provides first results regarding the role of individual, social and organisational diversity for the transition to HE. Here, we used structural equation modelling which allows to specify effects of all diversity factors in one model and at the same time to assess the measurement error. With these two analytical approaches, it was possible to draw a more complete picture of the various influences of diversity going beyond a single-factor analysis of the transition process.

However, apart from the need to further develop the theoretical assumption of intersecting levels of HE and diversity factors, some empirical limitations have to be taken into account. First, the study is based on cross-sectional data, which limits the causal interpretation of the results. Therefore, future studies should collect longitudinal data to investigate the student's perception of requirements and its relationships to individual, social, and organisational variables. Moreover, although the constructs examined in this study can be considered distinct from each other (i.e. self-efficacy, volition), common method bias cannot be ruled out because all variables were collected as self-report data at the same time (Podsakoff, MacKenzie, \& Podsakoff, 2012). Second, even though the total sample size is large and group-specific analyses are especially valuable, there are some rather small groups. First of all, the diversity of our sample in terms of the examined social factors is rather limited. That is plausible against the background of the definition for diversity and non-traditional students but might be the reason for hidden effects of social diversity on the perception of institutional requirements. The same applies to the insignificant results for medicine \& health despite the effect size. The only possible solution to enhance the power is to strive for even more cases in further research. Finally, future research could investigate additional factors in order to generate a more complete picture of the consequences of students' perception of the requirements, for example, including objective achievement measures in a longitudinal study design. 


\subsection{Practical implications}

With respect to practical implications, the identified profiles suggest that HE institutions could support their students' transition according to the perception of institutional requirements. In fact, the different levels of perceived challenges may serve as a guideline for the design of differential support in line with the diverse needs of first-year students. While one group of students in our study appears to easily handle the institutional requirements and may therefore profit from additional academic challenges, the other group would probably benefit from a holistic approach that addresses the full range of first-year challenges and provides particular support with regard to organising learning activities. However, our findings may not only encourage HE institutions to offer a rather broad portfolio of support activities, but they also suggest to provide guidance for first-year students to select appropriate types of support. Self-reflection tools (e.g., Bohndick, Kohlmeyer, \& Buhl, 2019; Nolden, 2019), that include the perception of institutional requirements could therefore be an additional means to facilitate the successful transition to HE.

For the design of the respective tools and support activities, HE institutions should also consider that the perception of requirements largely depends on individual factors. Therefore, first and foremost self-efficacy and volition should find promotion at several points in the first year to ensure successful transitions for all students. Studies on volitional strategies of first-year students (Trautwein \& Stolz, 2015), for example, may be used to design the respective support activities. At the same time, intervention studies and research on the effects of first-year support are needed in order to examine how the existing first-year support activities not only facilitate study success (Sneyers \& De Witte, 2018), but how they contribute to the development of the motivation, skills and strategies they seek to address (Robbins et al., 2009).

Last but not least, while structural barriers due to the students' social background must not be neglected in the design of first-year support, our study suggests to be careful not to stigmatize social groups of students. Next to individual factors they should rather follow Wong and Chiu (2019) and promote transparency with regard to the specific demands of the different disciplines and study programmes in order to enable students to better navigate the first-year challenges.

\section{Keypoints}

- The concept of first-year requirements serves as a gateway for investigating the role of diversity for the transition to higher education.

- We used latent profile analysis and structural equation modelling for further insights into the differential impact of several diversity factors.

- Students differ in the overall level of perceived challenges which are experienced either as easy or difficult.

- The perception of the first-year requirements is mainly associated with the individual diversity factors of self-efficacy and volition.

- There are differences between the disciplines. 


\section{References}

Asikainen, H., Hailikari, T., \& Mattsson, M. (2018). The interplay between academic emotions, psychological flexibility and self-regulation as predictors of academic achievement. Journal of further and higher education, 42(4), 439-453. https://doi.org/10.1080/0309877X.2017.1281889

Bandura, A. (1997). Self-efficacy: The exercise of control (Vol. 4). Times Books/ Henry Holt \& Co.

Barnat, M., Bosse, E., \& Mergner, J. (2017). Forschungsbasierte Qualitätsentwicklung für die Studieneingangsphase. Zeitschrift für Hochschulentwicklung, 12(3), 71-91.

Barnat, M., Bosse, E., \& Trautwein, C. (2017). The guiding role of theory in mixed-methods research: Combining individual and institutional perspectives on the transition to higher education. In J. Huisman \& M. Tight (Eds.), Theory and method in higher education research (Vol. 3, pp. 119). Emerald Publishing Limited. https://doi.org/10.1108/S2056-375220170000003001

Bartimote-Aufflick, K., Bridgeman, A., Walker, R., Sharma, M., \& Smith, L. (2016). The study, evaluation, and improvement of university student self-efficacy. Studies in Higher Education, 41(11), 1918-1942. https://doi.org/10.1080/03075079.2014.999319

Bernardo, A., Esteban, M., Fernández, E., Cervero, A., Tuero, E., \& Solano, P. (2016). Comparison of personal, social and academic variables related to university drop-out and persistence. Frontiers in Psychology, 7, Article 1610. https://doi.org/10.3389/fpsyg.2016.01610

Bohndick, C., \& Buhl, H. M. (2014). Auf dem Weg zur Professionalisierung: Anforderungen im Lehramtsstudium. Zeitschrift für Pädagogische Psychologie, 28(1), 63-68. https://doi.org/10.1024/1010-0652/a000119

Bohndick, C., Kohlmeyer, S., \& Buhl, H. M. (2019). Anstoß und Unterstützung der professionellen Weiterentwicklung überfachlicher Kompetenzen im Studium durch weiterentwicklungsorientiertes Online-Self-Assessment. Lehrerbildung auf dem Prüfstand, 12 (1), 19-31.

Bohndick, C., Rosman, T., Kohlmeyer, S., \& Buhl, H. M. (2018). The interplay between subjective abilities and subjective demands and its relationship with academic success. An application of the person-environment fit theory. Higher Education, 75(5), 839-854. https://doi.org/10.1007/s10734-017-0173-6

Bosse, E. (2015). Exploring the role of student diversity for the first-year experience. Zeitschrift für Hochschulentwicklung, 10(4), 45-66.

Brandstätter, H., Grillich, L., \& Farthofer, A. (2006). Prognose des Studienabbruchs. Zeitschrift für Entwicklungspsychologie und Pädagogische Psychologie, 38(3), 121-131. https://doi.org/10.1026/0049-8637.38.3.121

Bülow-Schramm, M. (2018). Faktoren für Studienerfolg - eine kritische Analyse von Bachelorstudiengängen. In N. Hericks (Ed.), Hochschulen im Spannungsfeld der BolognaReform: Erfolge und ungewollte Nebenfolgen aus interdisziplinärer Perspektive (pp. 311-334). Springer VS. https://doi.org/10.1007/978-3-658-21290-2_18

Coertjens, L., Brahm, T., Trautwein, C., \& Lindblom-Ylänne, S. (2017). Students' transition into higher education from an international perspective. Higher Education, 73(3), 357-369. https://doi.org/10.1007/s10734-016-0092-y

Dangoisse, F., De Clercq, M., Van Meenen, F. V., Chartier, L., \& Nils, F. (2019). When disability becomes ability to navigate the transition to higher education: a comparison of students with and without disabilities. European Journal of Special Needs Education, 35(4), 513-528. https://doi.org/10.1080/08856257.2019.1708642

De Clercq, M., Galand, B., \& Frenay, M. (2016). Transition from high school to university: a personcentered approach to academic achievement. European Journal of Psychology of Education, 32(1), 39-59. https://doi.org/10.1007/s10212-016-0298-5

De Clercq, M., Van Meenen, F., \& Frenay, M. (2020). Les écueils de la transition universitaire: validation française du questionnaire des obstacles académiques (QoA). Evaluer. Journal international de Recherche en Education et Formation. A paraître. 
Duchatelet, D., \& Donche, V. (2019). Fostering self-efficacy and self-regulation in higher education: a matter of autonomy support or academic motivation? Higher Education Research \& Development, 38(4), 733-747. https://doi.org/10.1080/07294360.2019.1581143

Ebert, J., \& Heublein, U. (2017). Studienabbruch bei Studierenden mit Migrationshintergrund. Eine vergleichende Untersuchung der Ursachen und Motive des Studienabbruchs bei Studierenden mit und ohne Migrationshintergrund auf Basis der Befragung der Exmatrikulierten des Sommersemesters 2014. Deutsches Zentrum für Hochschul- und Wissenschaftsforschung. https://www.dzhw.eu/pdf/21/bericht mercator.pdf

Gonida, E., \& Peixoto, F. (2019). SUnStAR IO1. Literature review and conceptualization. Aristotle University.

Haarala-Muhonen, A., Ruohoniemi, M., Parpala, A., Komulainen, E., \& Lindblom-Ylänne, S. (2017). How do the different study profiles of first-year students predict their study success, study progress and the completion of degrees? Higher Education, 74(6), 949-962. https://doi.org/10.1007/s10734-016-0087-8

Hell, B., Ptok, C., \& Schuler, H. (2007). Methodik zur Ermittlung und Validierung von Anforderungen an Studierende (MEVAS). Anforderungsanalyse für das Fach Wirtschaftswissenschaften. Zeitschrift für Arbeits- und Organisationspsychologie, 51(2), 8895. https://doi.org/10.1026/0932-4089.51.2.88

Heublein, U., Ebert, J., Hutzsch, C., Isleib, S., König, R., Richter, J., \& Woisch, A. (2017). Zwischen Studienerwartungen und Studienwirklichkeit - Ursachen des Studienabbruchs, beruflicher Verbleib der Studienabbrecherinnen und Studienabbrecher und Entwicklung der Studienabbruchquote an deutschen Hochschulen. Deutsches Zentrum für Hoch- und Wissenschaftsforschung. http://www.dzhw.eu/pdf/pub fh/fh-201701.pdf

Heublein, U., Richter, J., \& Schmelzer, R. (2020). Die Entwicklung der Studienabbruchquoten in $\begin{array}{llll}\text { Deutschland. } & \text { DZHW } & \text { Brief, } & 3,12 .\end{array}$ https://www.dzhw.eu/pdf/pub_brief/dzhw_brief_03 2020.pdf

Holmegaard, H. T., Madsen, L. M., \& Ulriksen, L. (2017). Why should European higher education care about the retention of non-traditional students? European Educational Research Journal, 16(1), 3-11. https://doi.org/10.1177/1474904116683688

Hußtegge, R. (2011). Selbstreguliertes Wollen als Bedingung für Studienerfolg an der Universität. Oldenburg.

Jänsch, V. K., \& Bosse, E. Messinstrument für die Wahrnehmung von Studienanforderungen (MWS). Zusammenstellung Sozialwissenschaftlicher Items Und Skalen (ZIS). https://doi.org/10.6102/zis263

Jansen, E. P. W. A. (2004). The influence of the curriculum organization on study progress in higher education. Higher Education, 47(4), 411-435. https://doi.org/10.1023/B:HIGH.0000020868.39084.21

Jenert, T., Postareff, L., Brahm, T., \& Lindblom-Ylänne, S. (2015). Editorial: Enculturation and development of beginning students. Zeitschrift für Hochschulentwicklung, 10(4), 9-21.

Kehm, B. M. (2010). Germany. In J. J.F. Forest \& P. G. Altbach (Eds.), International Handbook of Higher Education. Part One: Global Themes and Contemporary Challenges, Part Two: Regions and Countries (pp. 729-745). Springer.

Kyndt, E., Donche, V., Trigwell, K., \& Lindblom-Ylänne, S. (Eds.). (2017). Higher education transitions - Theory and research. Routledge.

Locke, E. A., Latham, G. P., \& Erez, M. (1988). The determinants of goal commitment. Academy of Management Review, 13(1), 23-39. https://doi.org/10.2307/258352

Marsh, H. W., Lüdtke, O., Trautwein, U., \& Morin, A. J. (2009). Classical latent profile analysis of academic self-concept dimensions: Synergy of person-and variable-centered approaches to theoretical models of self-concept. Structural Equation Modeling, 16(2), 191-225. https://doi.org/10.1080/10705510902751010

Mountford-Zimdars, A., Sabri, D., Moore, J., Sanders, J., Jones, S., \& Higham, L. (2015). Causes of Differences in Student Outcomes. HEFCE. https://www.research.manchester.ac.uk/portal/en/publications/causes-of-differences-instudent-outcomes-hefce(02e33718-9d04-4b8c-9f48-97443da93082)/export.html 
Nolden, P. (2019). Enhancing student self-reflection: The SRT scale inventory. https://doi.org/10.13140/RG.2.2.23089.53600

OECD. (2019). Education at a Glance 2019: OECD Indicators. OECD. https://doi.org/10.1787/f8d7880d-en

Pascarella, E. T., Pierson, C. T., Wolniak, G. C., \& Terenzini, P. T. (2004). First-generation college students. Additional evidence on college experiences and outcomes. The Journal of Higher Education, 75(3), 249-284. https://doi.org/10.1080/00221546.2004.11772256

Podsakoff, P. M., MacKenzie, S. B., \& Podsakoff, N. P. (2012). Sources of method bias in social science research and recommendations on how to control it. Annual Review of Psychology, 63, 539-569. https://doi.org/10.1146/annurev-psych-120710-100452

Richardson, M., Abraham, C., \& Bond, R. (2012). Psychological correlates of university students' academic performance: a systematic review and meta-analysis. Psychological Bulletin, 138(2), 353-387. https://doi.org/10.1037/a0026838

Robbins, S. B., Oh, I. S., Le, H., \& Button, C. (2009). Intervention effects on college performance and retention as mediated by motivational, emotional, and social control factors: Integrated meta-analytic path analyses. Journal of Applied Psychology, 94(5), 1163-1184. https://doi.org/10.1037/a0015738

Schindler, S. (2014). Wege zur Studienberechtigung - Wege ins Studium? Springer. https://doi.org/10.1007/978-3-658-03841-0

Schindler, S., \& Lörz, M. (2011). Mechanisms of social inequality development: Primary and secondary effects in the transition to tertiary education between 1976 and 2005. European Sociological Review, 28(5), 647-660. https://doi.org/10.1093/esr/jcr032

Schneider, M. \& Preckel, F. (2017). Variables associated with achievement in higher education: A systematic review of meta-analyses. Psychological Bulletin, 143(6), 565-600. https://doi.org/10.1037/bul0000098

Schuetze, H. G., \& Slowey, M. (2002). Participation and exclusion: A comparative analysis of nontraditional students and lifelong learners in higher education. Higher Education, 44(3), 309327. https://doi.org/10.1023/A:1019898114335

Sneyers, E., \& De Witte, K. (2018). Interventions in higher education and their effect on student success: A meta-analysis. Educational Review, 70(2), 208-228. https://doi.org/10.1080/00131911.2017.1300874

Tinto, V. (1987). Leaving college: Rethinking the causes and cures of student attrition. University of Chicago Press.

Tönnies, S., Plöhn, S., \& Krippendorf, U. (1996). Skalen zur psychischen Gesundheit (SPG).

Trautwein, C., \& Bosse, E. (2017). The first year in higher education - critical requirements from the student perspective. Higher Education, 73(3), 371-387. https://doi.org/10.1007/s10734-0160098-5

Trautwein, C., \& Stolz, K. (2015). 'Press on regardless!' -The role of volitional control in the first year of higher education. Zeitschrift für Hochschulentwicklung, 10(49, 123-143.

Ulriksen, L. (2009). The implied student. Studies in Higher Education, 34(5), 517-532. https://doi.org/10.1080/03075070802597135

Van Den Berg, M. N., \& Hofman, W. H. A. (2005). Student success in university education: A multimeasurement study of the impact of student and faculty factors on study progress. Higher Education, 50(3), 413-446. https://doi.org/10.1007/s10734-004-6361-1

Wallis, M., \& Bosse, E. (2020). Studienrelevante Heterogenität in der Studieneingangsphase am Beispiel der Wahrnehmung von Studienanforderungen. Beiträge zur Hochschulforschung, 42(3), 8-30.

Wong, B., \& Chiu, Y.-L. T. (2019). Exploring the concept of 'ideal' university student. Studies in Higher Education, https://doi.org/10.1080/03075079.2019.1643302 


\section{Appendix A}

Items of the MWS

(“Messinstrument für die Wahrnehmung von Studienanforderungen”, Jänsch \& Bosse, 2018)

content-related: academic mode

- Acquire academic language proficiency (e.g., for exams and papers)

- Adjust to scholarly mode (e.g., approach to the subject matter)

- Develop academic skills (e.g., reading strategies, formulate enquiry questions)

\section{content-related: subject interest \& appl. learning}

- Generate subject-related career goals (e.g., recognise professional relevance of subjects)

- Clarify study choice and subject interest (e.g., fit between interests and subject)

- Relate theory and practice (e.g., find examples of application)

\section{personal: learning activities}

- $\quad$ Find mode of learning (e.g., select appropriate methods for learning)

- Schedule learning activities (e.g., set time and duration)

- Manage the workload (e.g., tasks and reading assignments)

- Assess one's own performance and capacities (e.g., need for regeneration)

\section{personal: pressure to perform $\&$ failure}

- Cope with exam results (e.g., bad grades)

- Cope with pressure to perform (e.g., test anxiety, expectations)

- Deal with assessment conditions (e.g., grading practices, number of exams)

organisational: study organisation

- Handle course offer (e.g., schedule constraints, limited range of topics)

- Deal with institutional conditions (e.g., overcrowding, limited access)

- Find appropriate information and counselling services (e.g., contact person)

- Manage course selection (e.g., self-directed choice, follow guidelines)

\section{social: relationships \& teamwork}

- Build peer relationships (e.g., for study groups)

- Collaborate in teams (e.g., prepare group presentations)

- Organise teamwork (e.g., find group members)

- Cope with the social climate (e.g., handle competition) 